\title{
Appendix Villous Adenoma
}

National Cancer Institute

\section{Source}

National Cancer Institute. Appendix Villous Adenoma. NCI Thesaurus. Code C5512.

An adenoma arising from the appendix. It is characterized by the presence of villous epithelial structures and it is associated with dysplasia. 